\title{
EVALUATION OF CHITOSAN MICROPARTICLES CONTAINING CURCUMIN AND CROSSLINKED WITH SODIUM TRIPOLYPHOSPHATE PRODUCED BY SPRAY DRYING
}

\author{
Alexandre Luis Parize* \\ Universidade de Brasília, Campus Planaltina, 73300-000 Planaltina - DF, Brasil \\ Hellen Karine Stulzer \\ Departamento de Ciências Farmacêuticas, Universidade Federal de Santa Catarina, 88040-900 Florianópolis - SC, Brasil \\ Mauro César Marghetti Laranjeira, Inês Maria da Costa Brighente e Tereza Cristina Rozone de Souza \\ Departamento de Química, Universidade Federal de Santa Catarina, CP 476, 88040-900 Florianópolis - SC, Brasil
}

Recebido em 21/8/11; aceito em 11/1/12; publicado na web em 15/5/12

\begin{abstract}
The aim of this study was to encapsulate curcumin into chitosan, using sodium tripolyphosphate (TPP) as an ionic crosslinker by the spray drying method. The influence of TPP on the properties of the final product, such as solubility, morphology, loading efficiency, thermal behavior, swelling degree and release profiles, was evaluated. The microparticles had a spherical morphology $(0.5-20 \mu \mathrm{m})$ with no apparent porosity or cracks. Results indicated the formation of a polymeric network, which ensures effective protection for curcumin. Controlled-release studies were carried out at $\mathrm{pH} 1.2$ and 6.8, to observe the influence of $\mathrm{pH}$ on curcumin release while the mechanism was analyzed using the Korsmeyer-Peppas equation.
\end{abstract}

Keywords: chitosan; curcumin; spray drying.

\section{INTRODUCTION}

Curcumin (1,7-bis (4-hydroxy-3-methoxyphenyl)-1,6-heptadien-3,5-dione) is the major component $(\sim 80 \%)$ of rhizomes of Curcuma longa $L$. and saffron. This compound exhibits many important properties, serving as an antioxidant and anti-inflammatory, ${ }^{1-4}$ chemopreventive and chemotherapeutic in cancer treatment, for antiseptic use and skin healing. ${ }^{4-7}$ The other components of Curcuma longa rhizomes $L$. also have biological activity, notably demethoxycurcumin $(\sim 10$ to $15 \%)$ and bis-demethoxycurcumin $(\sim 5 \%) .{ }^{8}$

Reports in the literature show that curcumin has low solubility in pure water and aqueous acid solutions, but has good solubility in basic medium and in solvents such as ethanol, acetone, chloroform and dimethylsulfoxide. ${ }^{4}$ It is generally used in basic form in soluble formulations, since for use in water it needs to be emulsified or complexed. Curcumin application in aqueous solution is limited to the basic $\mathrm{pH}$ range. ${ }^{9,10}$ Curcumin solubility can be increased by chemical modification or derivatization, such as complexation or interaction with macromolecules, surfactants and copolymers. ${ }^{11}$ The spray drying technique represents a good alternative to obtain a soluble system for the industrial application of curcumin. ${ }^{11,12}$

This technique has been widely used in the food and pharmaceutical industries to produce granule formulations with specific properties for the development of tablets and to increase the solubility of compounds otherwise poorly soluble in water. Spray drying has also been employed in the development of mucoadhesive systems. ${ }^{13,14}$ The literature provides limited information regarding the association between curcumin and macromolecules, with reports principally involving the use of the biopolymer chitosan (Figure 1). ${ }^{15}$ Chitosan is a copolymer formed from units of 2-deoxy-N-acetyl-Dglucosamine and 2-deoxy-D-glucosamine linked through glycoside $\beta(1 \rightarrow 4)$ bonds. It is obtained from the alkaline deacetylation of chitin and is classified as a non-toxic, biocompatible and biodegradable polymer, and has been used in the biomedical field. In the food industry, the use of chitosan is currently being investigated in

*e-mail: alparize@unb.br a bid to obtain new formulations in which natural dye stability is guaranteed. ${ }^{16-18}$

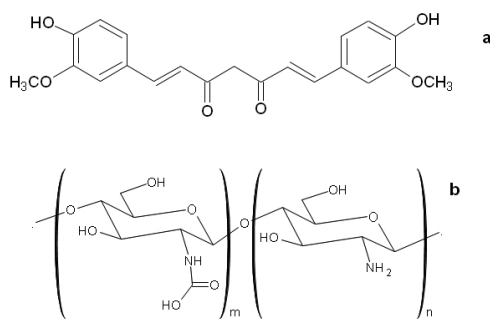

Figure 1. Chemical structures for curcumin (a) and chitosan (b)

The use of different techniques and crosslinking agents to produce chitosan microparticles is described in the literature, and the association of the spray drying technique and tripolyphosphate appears to be a promising alternative to promote differential curcumin delivery. Sodium tripolyphosphate (TPP) is a non-toxic crosslinker which can be used for the preparation of chitosan microparticles. The $\mathrm{PO}_{4}{ }^{3-}$ groups present in the TPP structure are easily attracted by protonated chitosan $\mathrm{NH}_{3}{ }^{+}$groups through ionic crosslinking. ${ }^{19-23}$

In view of these observations, the aim of this study was to develop a new curcumin/TPP/chitosan system using the spray-drying technique and to investigate the process variables, particularly the influence of the crosslinking agent on the microparticle characteristics.

\section{EXPERIMENTAL}

\section{Materials}

Fine chemical-grade chitosan derived from shrimp-shell chitin, with a degree of deacetylation of around $86 \%$ and molecular weight of around $122300 \mathrm{~g} \mathrm{~mol}^{-1}$, was purchased from Purifarma, São Paulo - SP, Brazil. The curcumin pigment was kindly supplied by Christen-Hansen Ind. \& Com. Ltd, Valinhos - SP, Brazil, as an oleoresin. Pure standard curcumin (99\%) was acquired from Merck, 
Darmstadt, Germany. All chemicals used were of pharmaceutical or analytical grade.

\section{Methods}

Spray drying of chitosan solutions containing curcumin

The chitosan $(2.0 \mathrm{~g})$ was dissolved in $100 \mathrm{~mL}$ of $5 \%$ acetic acid solution containing $1 \%$ of Tween- 80 for $12 \mathrm{~h}$. Dispersions containing $25 \mathrm{mg}$ of curcumin were homogenized in chitosan solutions for 2 $\mathrm{h}$, and $2 \%(\mathrm{w} / \mathrm{v})$ sodium tripolyphosphate was added to these solutions in different proportions $(0.5,1.0$ and $2.0 \mathrm{~mL})$. After the addition of TPP, the solutions remained for $2 \mathrm{~h}$ under stirring and were subsequently submitted to the spray drying process using a Buchi mini spray drier, model 191 (Buchi, Germany). The samples were atomized under standardized conditions: drying air at $180 \pm 5{ }^{\circ} \mathrm{C}$, air outlet temperature at $80 \pm 5{ }^{\circ} \mathrm{C}$, pressure of $5 \mathrm{bar}$, feed rate of $1.5 \%$ (1.5 mL sample/min), flow of $500 \mathrm{NL} / \mathrm{h}$ and manometric pressure of 5 bar. The drying process varied between 30-50 min. After drying, the product was collected in the form of a fine powder. The non-crosslinked sample was identified as $\mathrm{F}_{1}$ and samples containing $0.5,1.0$ and $2.0 \mathrm{~mL}$ of TPP were denoted $\mathrm{F}_{2}, \mathrm{~F}_{3}$ and $\mathrm{F}_{4}$, respectively.

\section{Morphology and size of microparticles}

In order to study the shape, size and external morphology of the microparticles, the samples were analyzed by scanning electron microscopy (SEM). Microparticles were placed on stubs and covered with a layer of gold/palladium to form a conductive film using a Baltec cool sputter coater (model SDC 005). Micrographs of the samples were obtained using a Philips scanning electron microscope (model XL 30) at an intensity of $10 \mathrm{kv}$ and different magnifications. Particle size was estimated from the measurement of around 200 particles, assuming spherical shape, lying within an arbitrarily chosen area of enlarged micrographs, using the Image Tool 3.0 software.

\section{Loading efficiency}

The curcumin content in the chitosan microparticles was determined by previous dissolution of the microparticles. Samples $(30 \mathrm{mg}$ ) were dissolved in $25 \mathrm{~mL}$ of $0.1 \mathrm{~mol} . \mathrm{L}^{-1}$ acetic acid at $\mathrm{pH} 4.0$ for $1.5 \mathrm{~h}$. After filtration, the concentration of curcumin in the acetic acid solution was determined on a Shimadzu UV-Vis spectrophotometer (model UV-1201), set at $429 \mathrm{~nm}$. The calibration curve was produced with a curcumin standard sample, purchased from Merck, dissolved in a solution composed of buffer solution $\mathrm{pH} 4.0$ and ethanol 80:20 $\left(y=0.0126+0.0794 x ; r^{2}=0.994\right)$. Loading efficiency tests were assayed in triplicate for each sample.

\section{Infrared spectroscopy}

The samples were analyzed by infrared spectroscopy using a Perkin Elmer infrared spectrometer (model FT-PC-160). The samples were prepared as $\mathrm{KBr}$ pellets, using 16 scans and a resolution of $8 \mathrm{~cm}^{-1}$.

\section{Thermogravimetric analysis}

The samples were analyzed with a Shimadzu thermogravimetric analyzer (TGA50, Kyoto, Japan) in a nitrogen atmosphere. The heating rate of the experiment was $10{ }^{\circ} \mathrm{C} \mathrm{min}{ }^{-1}$. Nitrogen flow was maintained at $50 \mathrm{~mL} \mathrm{~min}{ }^{-1}$ and samples of $12 \mathrm{mg}$ were used for all experiments.

\section{Differential scanning calorimetry}

DSC curves were obtained on a Shimadzu DSC-50 cell using aluminum crucibles containing around $12 \mathrm{mg}$ of samples, under

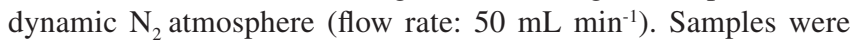

heated to $140{ }^{\circ} \mathrm{C}$ in order to evaporate the residual and adsorbed water (first run), cooled to ambient temperature and reheated. The temperature range for the second run was 25 to $300{ }^{\circ} \mathrm{C}$ with a heating rate of $10{ }^{\circ} \mathrm{C} \mathrm{min}^{-1}$. An empty aluminum pan was used as a reference. The DSC cell was calibrated with indium $\left(\mathrm{mp} 156.6^{\circ} \mathrm{C}\right.$; $\Delta$ Hfusion $\left.=28.54 \mathrm{~J} \mathrm{~g}^{-1}\right)$ and zinc $\left(\mathrm{mp} 419.6^{\circ} \mathrm{C}\right)$.

\section{Swelling degree}

The dry microparticles were initially weighed and then kept in $\mathrm{pH} 7.5$ buffer solutions. The solutions containing the microparticles were transferred to a Marconi mini-shaker incubator (model MA 832) and maintained under stirring at $25.0 \pm 0.1{ }^{\circ} \mathrm{C}$. After $24 \mathrm{~h}$, the solutions containing the microparticles were centrifuged at $1000 \mathrm{rpm}$, the supernatant was discarded and the bottles containing the remaining swollen microparticles weighed again. The swelling capacity of the microparticles was calculated using Equation 1:

$$
S D=\frac{W_{t}-W_{o}}{W_{o}} \times 100
$$

where $W_{t}$ and $W_{o}$, refer to the weights of the samples at time $t$ and in the dry state, respectively. The swelling data for the microparticles are given as the mean of three determinations.

\section{In vitro release studies}

Microparticles $(25 \mathrm{mg}$ ) were suspended in $25 \mathrm{~mL}$ of buffer solution: $\mathrm{pH} 1.2$ and 6.8. At predetermined time intervals, $3 \mathrm{~mL}$ of sample was withdrawn to determine the quantity of dye released and an equivalent amount of fresh dissolution media, pre-warmed to $25 \pm 5^{\circ} \mathrm{C}$, was used to replace the amount removed. The samples were analyzed at $429 \mathrm{~nm}$, by UV-Vis spectrophotometry. The percentage of dye released was calculated using a calibration curve produced for the standard curcumin purchased from Merck, dissolved in a solution comprising buffer solution and ethanol 80:20 $(\mathrm{pH} 1.2$ : $\mathrm{y}=0.0134+$ $0.0734 \mathrm{x} ; \mathrm{r}^{2}=0.998$ and $\mathrm{pH}=6.8: \mathrm{y}=0.0143+0.0774 \mathrm{x} ; \mathrm{r}^{2}=0.992$ ). All experiments were performed in triplicate. The results are expressed as cumulative curcumin release within the experimental time ( \pm standard deviation). In vitro release tests were carried out until total dissolution of the microparticles was attained.

\section{RESULTS AND DISCUSSION}

\section{Scanning electron microscopy (SEM)}

The atomized samples were morphologically characterized by SEM, including determination of the particle size distribution. The micrographs of the samples are shown in Figure 1S, supplementary material. The samples were found to have very similar external morphologies. All microparticles were spherical, without fissures or apparent porosity, and with a dense structure, a factor important for ensuring effective protection of the encapsulated material. The diameters of $\sim 200$ randomly selected particles were measured on enlarged SEM images. The size distribution in the samples was determined by manual measurement of the vertical and horizontal particle diameter. Size distribution has been widely used to describe the polydispersity of small particles, mainly in samples where smaller particle sizes are difficult to measure and some aggregation occurs. In this study, the particle size distribution ranged from $0.5-12 \mu \mathrm{m}$. A higher concentration of TPP in the solution increased the aggregation of the sample, but the average size of microparticles reduced only slightly. This finding can be attributed to an increase in the moisture content of the sample, which causes agglutination of the particles..$^{19}$ Isolated microparticles with sizes of up to $20 \mu \mathrm{m}$ were observed on all of the SEM analyses. 
Table 1. Properties and analysis of curcumin release data for curcumin /TPP/chitosan microparticles

\begin{tabular}{|c|c|c|c|c|c|c|}
\hline \multirow{3}{*}{ Formulation } & \multirow{3}{*}{$\mathrm{LE} \% \pm \mathrm{SD}^{\mathrm{a}}$} & \multirow{3}{*}{$\begin{array}{l}\text { Swelling } \\
\mathrm{SD}^{\mathrm{b}}\end{array}$} & \multicolumn{4}{|c|}{ Kinetic parameters } \\
\hline & & & \multicolumn{2}{|c|}{$\mathrm{pH} 1.2$} & \multicolumn{2}{|c|}{$\mathrm{pH} 6.8$} \\
\hline & & & $\mathrm{n}$ & $\mathrm{R}^{2}$ & $\mathrm{n}$ & $\mathrm{R}^{2}$ \\
\hline $\mathrm{F} 1$ & $72.99 \pm 1.37$ & $35.5 \pm 2.50$ & 0.85 & 0.991 & 0.31 & 0.991 \\
\hline $\mathrm{F} 2$ & $70.60 \pm 1.60$ & $30.4 \pm 1.21$ & 0.89 & 0.994 & 0.43 & 0.995 \\
\hline F3 & $69.31 \pm 1.88$ & $21.5 \pm 1.72$ & 0.92 & 0.997 & 0.37 & 0.992 \\
\hline $\mathrm{F} 4$ & $62.36 \pm 1.36$ & $15.2 \pm 0.73$ & 1.39 & 0.998 & 0.41 & 0.996 \\
\hline
\end{tabular}

${ }^{\mathrm{a}}$ Loading Efficiency \pm Standard Deviation, $\mathrm{n}=3$. ${ }^{\mathrm{b}}$ Time required to obtain microparticles with constant mass in buffer solution $\mathrm{pH} 7.5 ; 24 \mathrm{~h}, \mathrm{n}=3$.

Desai and Park ${ }^{19}$ reported that an increase in the volume or concentration of TPP promotes a loss in microparticle sphericity, stimulating a rugose surface aspect and agglomeration. These characteristics were also reported by Liu et al. ${ }^{23}$ who confirmed reduced microparticle sphericity when samples were prepared with chemical crosslinkers (glutaraldehyde and formaldehyde), compared with the ionic crosslinking agent TPP.

\section{Loading efficiency}

Comparative data on curcumin loading efficiencies for the different samples is given in Table 1.

The results indicate that the loading efficiency ranged from 62.36 to $72.99 \%$. With high additions of crosslinking agent the loading efficiency decreased, probably due to the presence of particles with an irregular surface which can cause losses during the spray drying process. ${ }^{19,21}$ Another important factor associated with a higher TPP concentration was the formation of an effective polymeric network which can promote the exposure of the compound to degradation factors. Paradkar et al. ${ }^{13}$ described the successful encapsulation of curcumin with poly(vinyl)pyrrolidone as the encapsulating agent, using the spray drying technique to develop physical mixtures and solid dispersions of curcumin and PVP. The authors described good solubility for the solid dispersions developed in their study. Similar results have been reported by Desai and Park ${ }^{21}$ for vitamin C microencapsulation and by Anal et al. ${ }^{22}$ for ampicilin microencapsulation. These authors suggested that with increasing TPP addition to the formulations, the number of phosphate groups involved in the crosslinking process increases, consequently reducing the amount of chitosan amino groups that can interact with the drug. A reduction in encapsulation efficiency of the chitosan/TPP system has been reported by Liu et al. ${ }^{23}$ and by Desai and Park ${ }^{20}$ for acetaminophen microencapsulation using a chitosan/TPP system.

\section{Fourier transform infrared spectroscopy (FT-IR)}

In Figure 2 depicts the FT-IR spectra for chitosan, curcumin and the microparticles. The FT-IR spectra for chitosan powder (Figure 2a) show characteristic absorption bands at 3443, 2923, and $2867 \mathrm{~cm}^{-1}$, which represent the presence of an $\mathrm{OH}$ group, a $\mathrm{CH}_{2}$ group and a $\mathrm{CH}_{3}$ group, respectively. $\mathrm{C}=\mathrm{O}$ stretching (amide I) peak at $1659 \mathrm{~cm}^{-1}$ representing the structure of $\mathrm{N}$-acetylglucosamine while the $\mathrm{NH}_{2}$ stretching (amide II) peak at $1569 \mathrm{~cm}^{-1}$ associated with the glucosamine functional group were also present. ${ }^{4}$

The spray-dried chitosan spectra (Figure $2 b$ ) show strong peaks at $1550 \mathrm{~cm}^{-1}$. In addition, the strong peak at $1500-1600 \mathrm{~cm}^{-1}$ and the weak peak near the $1400 \mathrm{~cm}^{-1}$ region were attributed to asymmetric and symmetric carboxylate anion stretching, respectively. ${ }^{24,25}$ The carbonyl stretching peak at $1659 \mathrm{~cm}^{-1}$ (amide I peak) disappeared

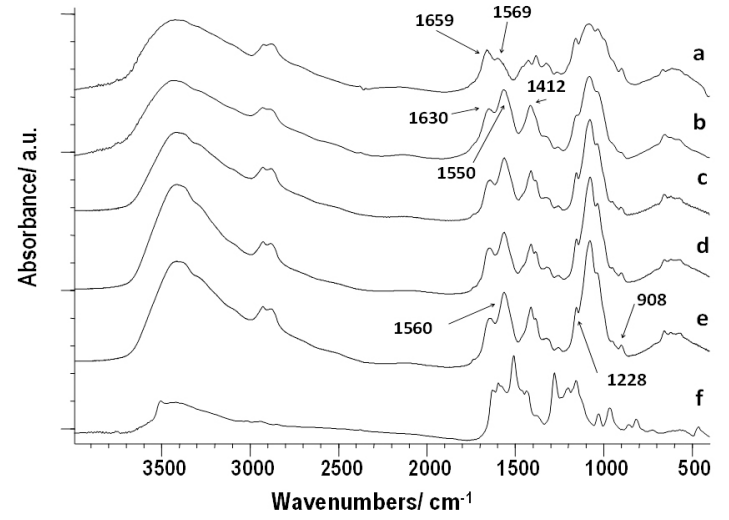

Figure 2. FT-IR of chitosan $(a), F_{1}(b), F_{2}(c), F_{3}(d), F_{4}(e)$ and curcumin $(f)$

and a new peak near $1630 \mathrm{~cm}^{-1}$ assigned to an asymmetric $\mathrm{NH}_{3}^{+}$ bending was observed. ${ }^{26}$

The FT-IR curcumin spectrum (Figure 2e) shows characteristic absorption bands at $3451 \mathrm{~cm}^{-1}$ which represent phenolic $\mathrm{OH}$ at $1620 \mathrm{~cm}^{-1}$, the $\mathrm{C}=\mathrm{O}$ stretching peak of conjugated ketone at 1562 and $1420 \mathrm{~cm}^{-1}, \mathrm{C}=\mathrm{C}$ stretching of aromatic and aliphatic groups at $1380 \mathrm{~cm}^{-1}, \mathrm{CH}_{3}$ stretching peaks present in the dye and the $\mathrm{C}-\mathrm{O}-\mathrm{C}$ stretching peak of ether at $1070 \mathrm{~cm}^{-1} .^{27}$

In the FT-IR spectra for the microparticles containing TPP (Figure $2 \mathrm{c}-\mathrm{e})$ the interaction between phosphate groups and protonated chitosan amine groups was evident, represented by stretching close to $1560 \mathrm{~cm}^{-1}$. These results are in agreement with similar data reported in the literature. ${ }^{28,29}$ Additional stretching vibrations at 1228 and 908 $\mathrm{cm}^{-1}$ have been reported for phosphate groups present in the samples. Other evidence of the presence of TPP is the appearance of a new band at $1150 \mathrm{~cm}^{-1},{ }^{30,31}$ indicating that the TPP phosphate groups were linked to the chitosan through intermolecular interactions.

\section{Thermogravimetric analysis (TG/DTG)}

Three stages of weight loss were observed for all samples (Figure 3 and Table 1S, supplementary material), the first being responsible for a dehumidification process and the second related to evaporation of internally bound water in the polymer structure. The non-crosslinked sample presented a third stage at $302{ }^{\circ} \mathrm{C}$, due to polymer decomposition. The curcumin standard had three stages of mass loss, the first at $67{ }^{\circ} \mathrm{C}$ related to dehumidification, and the second and the third at 321 and $402{ }^{\circ} \mathrm{C}$, related to the curcumin degradation, respectively. ${ }^{11}$

Increasing the amount of TPP in the samples decreased the thermal stability due to effective polymeric network formation. Similar profiles have been reported by Laus et al. ${ }^{29}$ and Stulzer et al..${ }^{32} \mathrm{~A}$ high TPP concentration in the microparticles promotes interaction between $\left(\mathrm{PO}_{4}\right)^{3-}$ and $\mathrm{NH}_{3}{ }^{+}$resulting in a more effective polymeric network, but also leads to low thermal stability. 


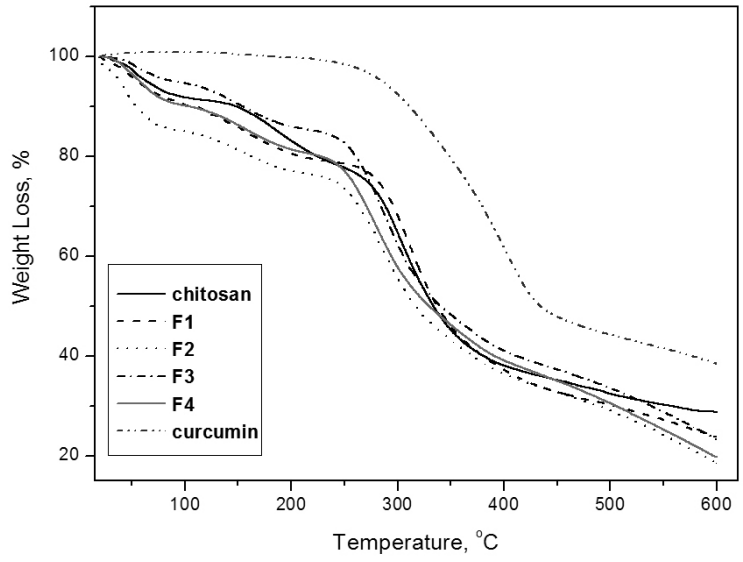

Figure 3. Thermogravimetric curves for: a) spray-dried chitosan, b) $F_{1}, c$ ) $F_{2}$, d) $\left.F_{3}, e\right) F_{4}$ and f) curcumin

\section{Differential scanning calorimetry (DSC)}

DSC curves are shown in Figure 4. For pure chitosan, the glass transition temperature $(\mathrm{Tg})$ was $100.4{ }^{\circ} \mathrm{C}$. The standard chitosan produced in the spray drying method has a Tg of $125^{\circ} \mathrm{C}$, suggesting that the addition of acetic acid to the preparation promotes high rigidity of the sample. The curcumin addition in $\mathrm{F}_{1}$ shifted the $\mathrm{Tg}$ to $91.30^{\circ} \mathrm{C}$, demonstrating that the dye is located between the polymeric chains, and increased the free volume and mobility of the system. The curcumin DSC curve shows an endothermic peak at $172{ }^{\circ} \mathrm{C}$ corresponding to the pigment melting point. ${ }^{27}$

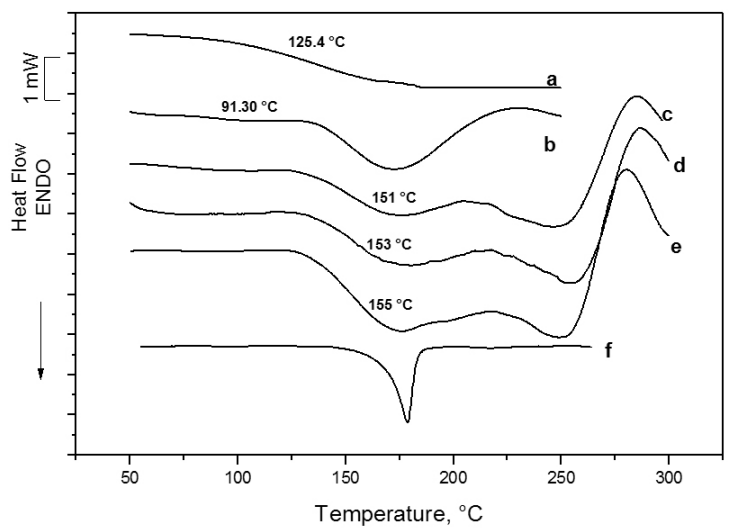

Figure 4. DSC curves for: a) spray-dried chitosan, b) $\left.F_{1}, c\right) F_{2}$, d) $\left.F_{3}, e\right) F_{4}$ andf) curcumin

DSC curves for $\mathrm{F}_{2}, \mathrm{~F}_{3}$ and $\mathrm{F}_{4}$ exhibited high Tg values, ranging from 151 to $155^{\circ} \mathrm{C}$. This finding suggests that the addition of TPP to the samples promotes a structural change, due to ionic crosslinking in the microparticles. Papadimitriou et al..$^{33}$ also reported changes in the $\mathrm{Tg}$ values for nanoparticles containing dorzolamide hydrochloride and pramipexole hydrochloride, crosslinked with TPP. These studies presented a $\mathrm{Tg}$ of $190{ }^{\circ} \mathrm{C}$, while for the non-crosslinked nanoparticles the $\mathrm{Tg}$ was $157^{\circ} \mathrm{C}$. An effective polymeric network was formed when a crosslinked system was obtained, thus, curcumin was internally retained to a greater extent. This results in the shifting of the curcumin fusion peak to a higher temperature of around 250 ${ }^{\circ} \mathrm{C}$, suggesting a possible interaction between chitosan and curcumin. Curcumin binds to the new polymeric network via hydrogen bonds, promoting greater pigment dispersion and stability. Stulzer et al. ${ }^{32}$ observed similar profiles in a study on chitosan/TPP used for acyclovir microencapsulation.

\section{Swelling degree and in vitro release studies}

Table 1 shows the swelling degree of the samples containing the crosslinking agent. It has been reported in the literature that the swelling ability of spray-dried chitosan is higher than that of pure chitosan. When the chitosan is crosslinked, the swelling ability of the samples is reduced and the matrices more rigid. Ionic interactions between the negative charges of the crosslinker (TPP) and positively charged groups of chitosan are the main interactions occurring within the network. The swelling capacity of spray-dried chitosan microspheres crosslinked with different volumes of TPP solution was $\mathrm{pH}$ -dependent. At pH 1.2, the samples swelled very quickly, leading to fast dissolution of the samples after $1 \mathrm{~h}$. However, swelling at $\mathrm{pH} 6.8$ was slower. At pH 6.8, as the volume of added TPP solution increased, the swelling capacity of spray-dried chitosan microspheres decreased considerably (Table 1). These results suggest that a more tightly crosslinked chitosan matrix does not swell (lower water uptake) as much as a loosely crosslinked chitosan matrix. With a lower volume of TPP, the chitosan network is loose and has a high hydrodynamic free volume to accommodate more of the solvent molecules, thereby inducing chitosan-TPP matrix swelling. ${ }^{19-21}$

In vitro release profiles for different curcumin/TPP/chitosan microparticles are depicted in Figures 5 and 6 . The results clearly indicate that the formulations had a differentiated pattern of release. Figure 5 shows that there was fast release of the curcumin at pH 1.2 in comparison with $\mathrm{pH} 6.8$ (Figure 6). At pH 1.2, the total release of curcumin was observed due to the complete dissolution of the microparticles while at $\mathrm{pH} 6.8$ the curcumin was completely released by diffusion through the swollen polymeric matrix of the microparticles. The main difference observed in the release assays carried out at different $\mathrm{pH}$ values is that, at $\mathrm{pH} 1.2$, the microparticles dissolved in the medium had a low swelling degree, whereas at $\mathrm{pH}$ 6.8 the dye was released through a diffusion process, since swelling of the polymeric system occurred. For samples containing TPP, an increase in the amount of crosslinking agent promoted slower dye release from the microparticles at both $\mathrm{pH}$ values.

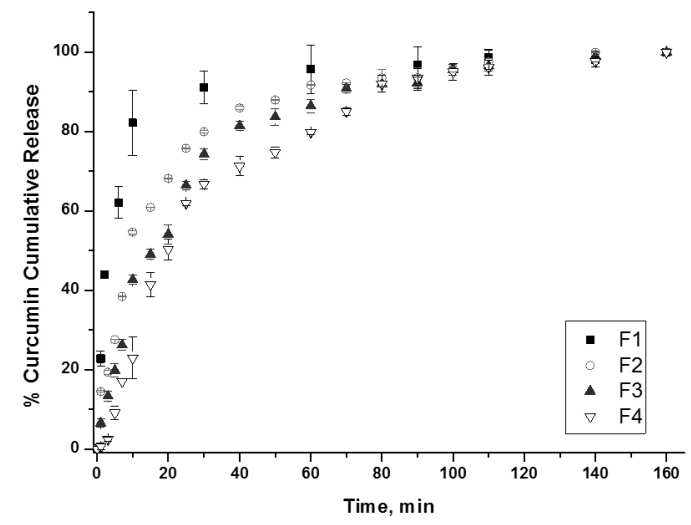

Figure 5. Dissolution profiles of $F_{1}, F_{2}, F_{3}$ and $F_{4}$ in hydrochloric acid buffer (pH 1.2)

For all of the controlled-release experiments, the linearization of the release curve was performed and mathematical modeling carried out to investigate the mechanism involved in the curcumin release. The Korsmeyer-Peppas model, a semi-empirical model correlating drug release with time through a simple exponential equation for the fraction of drug released, has previously been used to evaluate drug release from controlled-release polymeric devices. This model is particularly useful when the drug release mechanism is unknown or when there is more than one release mechanism. ${ }^{34,35}$ 


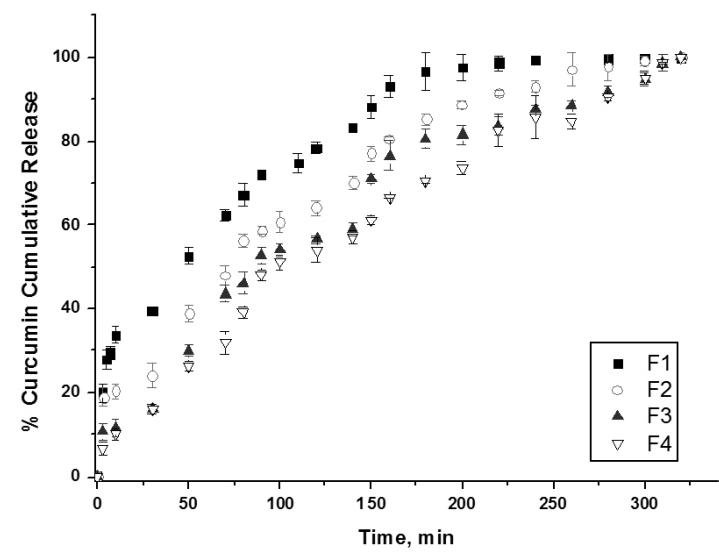

Figure 6. Dissolution profiles of $F_{1}, F_{2}, F_{3}$ and $F_{4}$ in phosphate buffer ( $p H$ 6.8)

The Korsmeyer-Peppas model (Equation 2) is described below:

$$
\frac{\mathrm{Mt}}{\mathrm{M} \infty}=k \cdot t^{n}
$$

where $M t / M_{\infty}$ is the proportion of drug released at time $t, k$ is the kinetic constant, and the exponent $n$ has been proposed as indicative of the release mechanism. In this context, $n \leq 0.43$ indicates Fickian release and $n=0.85$ indicates a purely relaxation-controlled delivery referred to as Case II transport. Intermediate values $0.43<n<0.85$ indicate an anomalous behavior (non-Fickian kinetics corresponding to coupled diffusion/polymer relaxation). ${ }^{36,37}$ Occasionally, values of $n>0.85$ have been observed and regarded as super Case II kinetics. ${ }^{38,39}$ The linear form of Equation 1, plotting $\ln M t / M \infty$ against ln $t$, yielded the diffusion exponential $(n)$, the Pearson coefficient $\left(r^{2}\right)$ and the diffusion constant $(k)$.

The investigation into the mechanism of curcumin release from curcumin/TPP/chitosan microparticles indicated that the dye is released from the microparticles at $\mathrm{pH} 1.2$ via the super Case II mechanism ( $\mathrm{n}$ value in the range 0.5 to 1.39 ), which involves simultaneous contributions from dissolution, relaxation of the polymeric chain, erosion and swelling of the chitosan. However, at pH 6.8, the samples presented a Fickian mechanism $(n \leq 0.43)$ of curcumin release, indicating that the dye is released from the microparticles by diffusion through the swollen polymeric matrix.

These results suggest that the use of TPP as a crosslinking agent is an appropriate means of controlling dye release from chitosan microparticles (Table 1), since an increase in concentration of TPP in the crosslinking process promotes a decrease in curcumin release rate. ${ }^{40}$ Similar release profiles were observed by Desai and Park ${ }^{21}$ for vitamin C release from TPP/chitosan systems and by Stulzer et al..$^{32}$ in acyclovir microparticles.

\section{CONCLUSIONS}

In this study, chitosan microparticles containing curcumin crosslinked with TPP were efficiently prepared in one step using the spray drying technique. The results obtained indicated that curcumin release is modulated by addition of higher concentrations of TPP. Also, the dye was found in an amorphous and dispersed state at the molecular level in the microparticles, promoting an increase in its solubility in aqueous solutions. Solubility is a fundamental parameter in terms of promoting any effect impacting the application of the dye. Thus, an increase in the solubility characteristic is an important step toward the future use of curcumin for different purposes.

\section{SUPPLEMENTARY MATERIAL}

Available at http://quimicanova.sbq.org.br, in the form of a PDF file, with free access.

\section{ACKNOWLEDGEMENTS}

The authors acknowledge the Brazilian Government funding agency Conselho Nacional de Desenvolvimento Científico and Tecnológico $(\mathrm{CNPq})$ for financial support and for fellowships; and the Chemistry Department at UFSC for fellowships.

\section{REFERENCES}

1. Mehta, K.; Pantazis, P.; McQueen, T.; Aggarwal, B. B.; Anti-cancer Drugs 1997, 8, 470.

2. Masuda, T.; Hidaka, K.; Shinohara, A.; Maekawa, T.; Takada Y.; Yamaguchi, H.; J. Agric. Food Chem. 1999, 47, 71.

3. Motterlini, R.; Foresti, R.; Bassi, R.; Green, C. J.; Free Radical Biol. Med. 2000, 28, 1303.

4. Sharma, R. A.; Gescher, A. J.; Steward, W. P.; Eur. J. Cancer 2005, 41, 1955.

5. Aggarwal, B. B.; Kumar, A.; Bharti, A. C.; Anti-cancer Res. 2003, 23, 363.

6. Joe, B.; Vijaykumar, M.; Lokesh, B. R.; Crit. Rev. Food Sci. Nutr. 2004, 44, 97.

7. Duvoix, A.; Blasius, R.; Delhalle, S.; Schnekenburger, M.; Morceau, F.; Henry, E.; Dicato, M.; Diederich, M.; Cancer Lett. 2005, 223, 181.

8. Downham, A.; Collins, P.; Int. J. Food Sci. Technol. 2000, 35, 5.

9. Wang, F.; Yang, J. H.; Wu, X.; Liu, S. F.; Spectrochim. Acta, Part A 2005, 61, 2650.

10. Price, L. C.; Buescher, R. W.; J. Food Sci.1997, 62, 267.

11. Parize, A. L.; Heller, M.; Fávere, V. T.; Laranjeira, M. C. M.; Brighente, I. M. C.; Micke, G. A.; Souza, T. C. R.; Latin Am. J. Pharm. 2009, 28, 19.

12. Prachayawarakorn, J.; Kryratsamee, W.; J. Appl. Polym. Sci. 2007, 106, 1526.

13. Paradkar, A.; Ambike, A. A.; Jadhav, B. K.; Mahadik, K. R.; Int. J. Pharm. 2004, 271, 281.

14. Parize, A. L.; Souza, T. C. R.; Brighente, I. M. C.; Fávere, V. T.; Laranjeira, M. C. M.; Spinelli, A.; Longo, E.; Afric. J. Biotechnol. 2008, 7, 3107.

15. Vidyalakshmi, K.; Rashmi, K. N.; Kumar, T. M. P.; Siddaramaiah.; J. Macromol. Sci., Part A: Pure Appl. Chem. 2004, 41, 1115.

16. Chang, E. J.; Choi, S. W.; No, H. K.; J. Food Sci. Nutr. 2000, 5, 1.

17. Higuera-Ciapara, I.; Valenzuela, L. F.; Goycoolea, F. M.; Monal, A.; Carbohydr. Polym. 2004, 56, 41.

18. Souza, T. C. R.; Parize, A. L.; Brighente, I. M. C.; Fávere, V. T.; Laranjeira, M. C. M.; J. Microencapsulation 2005, 22, 511.

19. Desai, K. G. H.; Park, H. J.; J. Microencapsulation 2005, 22, 377.

20. Desai, K. G. H.; Park, H. J.; Drug Dev. Res. 2005, 64, 114.

21. Desai, K. G. H.; Park, H. J.; J. Microencapsulation 2005, 22, 179.

22. Anal, A. K.; Stevens, W. F.; Remuñán-López, C.; Int. J. Pharm. 2006, $312,166$.

23. Liu, C.; Desai, K. G. H.; Tang, X.; Chen, X.; Drying Technol. 2006, 24 , 769.

24. Nunthanid, J.; Laungtana-Anan, P.; Sriamomsak, P.; Limmatvapirat, S.; Puttipipatkhachom, S.; Lim, L. Y.; Khor, E.; J. Controlled Release 2004, 99, 15.

25. Orienti, I.; Cerchiara, T.; Luppi, B.; Bigucci, F.; Zuccari, G.; Zecchi, V.; Int. J. Pharm. 2002, 238, 51.

26. Silverstein, R. M.; Webster, F. X.; Spectrometry Identification of Organic Compounds, $6^{\text {th }}$ ed., John Wiley and Sons: New York, 1998. 
27. Pan, C. J.; Tang, J. J.; Weng, Y. J.; Wang, J.; Huang, N.; J. Controlled Release 2006, 116, 42.

28. Xu, Y.; Du, Y.; Int. J. Pharm. 2003, 250, 215.

29. Laus, R.; Laranjeira, M. C. M.; Martins, A. O.; Fávere, V. T.; Pedrosa, R. C.; Benassi, J. C.; Geremias, R.; Quim. Nova 2006, 29, 34.

30. Lee, S. T.; Mi, F. L.; Shen, Y. J.; Shyu, S. S.; Polymer 2001, 42, 1879.

31. Jain, A.; Jain, S. K.; Eur. J. Pharm. Sci. 2008, 35, 404.

32. Stulzer, H. K.; Tagliari, M. P.; Parize, A. L.; Silva, M. A. S.; Laranjeira, M. C. M.; Mater. Sci. Eng., C 2009, 29, 387

33. Papadimitriou, S.; Bikiaris, D.; Avgoustakis, K.; Karavas, E.; Georgarakis, M.; Carbohydr. Polym. 2008, 73, 44
34. Korsmeyer, R. W.; Gurny, R.; Doelker, E.; Buria, P.; Peppas, N. A.; Int. J. Pharm. 1983, 15, 25.

35. Costa, P.; Lobo, J. M. S.; Eur. J. Pharm. Sci. 2001, 13, 123.

36. Ritger, P. L.; Peppas, N. A.; J. Controlled Release 1987, 5, 23.

37. Ritger, P. L.; Peppas, N. A.; J. Controlled Release 1987, 5, 37.

38. Ranga, R.; Devi, K. D.; Buri, P.; Drug Dev. Ind. Pharm. 1988, 14, 2299.

39. Munday, D. L.; Cox, P. L.; Int. J. Pharm. 2000, 203, 179.

40. Li, X. L.; Kong, X. K.; Shi, S. Z. X.; Guo, G.; Wei, Y.; Qian, Z.; BMC Biotechnol. 2008, 8, 89. 